\title{
Comparison of card and desktop versions of a game about periodic properties.
}

\author{
Gabriela Trindade Perry • Departamento de Design e Expressão Gráfica | UFRGS • \\ gabriela.perry@ufrgs.br \\ Marcelo Leandro Eichler•Instituto de Química | UFRGS • exlerbr@yahoo.com.br
}

\begin{abstract}
This paper presents the results of a comparison study of the learning outcomes of two versions of the same educational game about periodic properties of chemical elements, called Xe nubi. Our aim was to test C lark's "method-not-media" hypothesis, which predicts there will be no difference in student performance if the method of instruction is the same, regardless of media types. This study took place in a public technical school in southern Brazil and sought differences in pre-test and post-test scores between groups that played Xenubi as printed cards or on the computer. The results point to no significant difference between the two groups, although there was difference in the pre and post-test, indicating the game was effective. This is a confirmation of $\mathrm{C}$ lark's hypothesis.
\end{abstract}

Keywords: multimedia, chemistry education, card games, educational games

\section{Resumo}

Este artigo apresenta os resultados de um estudo que compara os resultados de aprendizagem de duas versões do mesmo jogo educativo sobre propriedades periódicas de elementos químicos, chamado Xenubi. Nosso objetivo era testar a hipótese "método-não- mídia" de C lark, que prevê que não haverá diferença no desempenho de um aluno se o método de instrução for o mesmo, independentemente do tipo de mídia utilizado. Este estudo aconteceu em uma escola técnica pública no sul do Brasil e buscou diferenças nos resultados dos pré e pós-teste de grupos que jogaram com cartas impressas ou no computador. Os resultados não indicam diferença significativa entre os dois grupos, embora tenha havido diferença no pré e pós-teste, indicando que o jogo foi efetivo. Este resultado é uma confirmação da hipótese de Clark.

Palavras-chave: multímidia, educação em química, jogos de carta, jogos educacionais

\section{Introduction}

In science domains - especially in chemistry - learning concepts and methods involve understanding and conceptually linking different representational forms of the target phenomena. This is the rationale behind the idea of simultaneously providing multiple representational models of the same phenomena (Kozma \& Russel, 1997; Gabel, 1993) - the point is to address naive conceptions students (and teachers) have about chemistry. 
Regarding the subject of the game developed for this study - periodic trends - it is widely recognized as one fundamental idea in Science (Liu \& Dwi-Nugroho, 2012). Given that the design of period ic tables regards the atomic level, science teachers need to develop explicit instructions on the periodic system. Farret et al (2010) consider that trends in 1st ionization energy, preferred oxidation states and reactivity between different elements are s tandard chemical concepts that should be well- established long before students reach university. For Demircioğlu et al. (2009), the Periodic Table plays a significant role in both understanding of the chemical elements and predicting their features. The s tudents who know the properties of typical members of each of the eight principal groups, are able to effectively predict their physical and chemical properties, i.e. boiling point, melting point, chemical bonding, intermolecular forces and so on. Next we present some of the many learning chemistry games which were designed from 1930 to 2014.

\subsection{Card-based games for chemistry education.}

Chemistry teachers have been using card games for a long time. The oldest example we have found is from 1930 - a game called "The game of chemists" - made up of four sets of cards, each with the name of famous chemists, description of their most famous experiments, its resulting discovery or law and on the date of the chemist's death - and the player has to find a correct ma tch (Elking, 1930). Card games like this are very common, as they usually have simple rules and are inexpensive. Some example of educational chemistry card games about chemical elements, periodic properties and the periodic table are: ChemMend (Martí-Centelles \& Rubio-Magnieto, 2014), in which players have to pile cards according to their groups and periods; Cheminoes (Moreno et al., 2014), about the relationship between chemical element (S), valence (V), atomic number (Z), and chemical symbol, where the goal is to place cards in a coherent sequence (for example, $\mathrm{H}$ symbol card has to be placed next to a card with $Z=1$ ); Elements (Sevcik, Hicks \& Schultz, 2008), where students have to recognize and correlate the names and symbols of the most significant chemical elements; The Organic Functional Group Card Deck (Welsch, 2003) which aims to help visually oriented students (fine or performing arts majors and communication majors) to recognize the names and structures of 13 common organic functional groups. No measurements of efficiency are reported in those studies.

\section{Is it the medium or is it the method?}

In the early 80's, Richard C lark has posed his "method-not-media" hypothesis; he claimed that since that are no cognitive skills dedicated or tuned to process digital media, the same learning outcomes should be achievable via other teaching methods, and that the positive results of studies comparing the delivery of the same content trough different media were, in fact, due to uncontrolled variables, like an effect of the novelty of the technology (C lark, 1983, 1994). More recently, Joy \& Garcia (2000) and Lazonder \& Ehrenhard (2014) pointed out the same need for caution when analyzing studies which evaluate learner performance when digital media is used. Sung \& Mayer 
(2003) directly tested C lark's hypothesis, comparing the same instructional material, designed for personal computers and mobile devices, but changing the multimedia design principles (Mayer, 2001; Mayer \& Moreno, 1998), across four groups. They concluded that across both media the groups where Mayer's Multimedia Design Principles were adequately applied outperformed the standard group. F urió et al. (2015) found the same learning gains when comparing an $\mathrm{P}$ hone game for learning the water cycle with the traditional classroom lesson.

Standing for the position that multimedia has the potential to foster learning, Robert Kozma replied to Clark's argumentation (Kozma, 1991, 1994). Kozma argues that multimedia not only has an economical advantage - it can deliver instruction to many, can be reutilized and requires less infrastructure - but also that the computer connects the learner with the real world by supporting the construction of the relationship between various symbol systems (embedded in the computerized instructional unity) and the real world they represent. Contradicting $\mathrm{C}$ lark's claims, he states the computer can influence the mental representations and cognitive processes of learners (Kozma, 1991, p.22). In this framework, we state our hypothesis as "the learning outcomes of the group playing Xenubi on the computer will be the same as that of the group playing with printed cards". Xenubi is a game about periodic trends. We have made a card and a computer version to test the hypothesis that the media (computer or cards) will have no effect on learning outcomes - we kept the method of instruction the same for both versions.

\section{Xenubi, a game about periodic trends.}

Xenubi is a card-based game about periodic trends, a traditional theme in high school and undergraduate chemistry courses. It is a casual game: easy to learn, with simple rules and easy to remember how to play. Casual games are characterized by fast and short missions/rounds, which do not require the player to spend several hours playing to advance (Fortugno, 2008). The didactical strategy was to relate the Periodic Table structure to ato mic models, so students could understand why it is called "periodic". "Xenubi" [Je-nu-bi] is not an existing word in Portuguese: it was created by the conjunction of "chem." - short for "chemistry" and the slang "newbie; noob" - used by gamers. In Xenubi, the player receives 6 cards, each representing a chemical element. Each card has the numerical value of 6 properties: atomic radius, first ionization potential, electron affinity, electronegativity, melting point, and density. These are the properties most teachers in Brazil use to address the subject of Periodic Table of elements or chemical periodicity. The player sees, in a Periodic Table, his and the opponent's (the computer or a classmate's) element, and has to choose among those 6 properties the one he thinks his element has a higher value. The player should infer this by using the knowledge about periodicity and the location of both elements in the periodic table. The user wins if he gets all cards from the computer or his classmate, and loses if he loses all his cards to the computer (the computer does not plays any rounds). On the computer version, the opponent is represented by Dr. Henry Moseley, the scientist who proposed the organization of the periodic table via atomic number (Scerri 
2007).

The mechanics are similar to the card game $S$ uper Trump®. F igure 1 has print screens of Xenubi' s most important screens of the computer version, and F igure 2 shows a printed card.

To simulate the position of the opponent's chemical element in the periodic table (as in the computer version of the game), a periodic table has to be given along with the card game, and both players should say the name of their elements out loud.
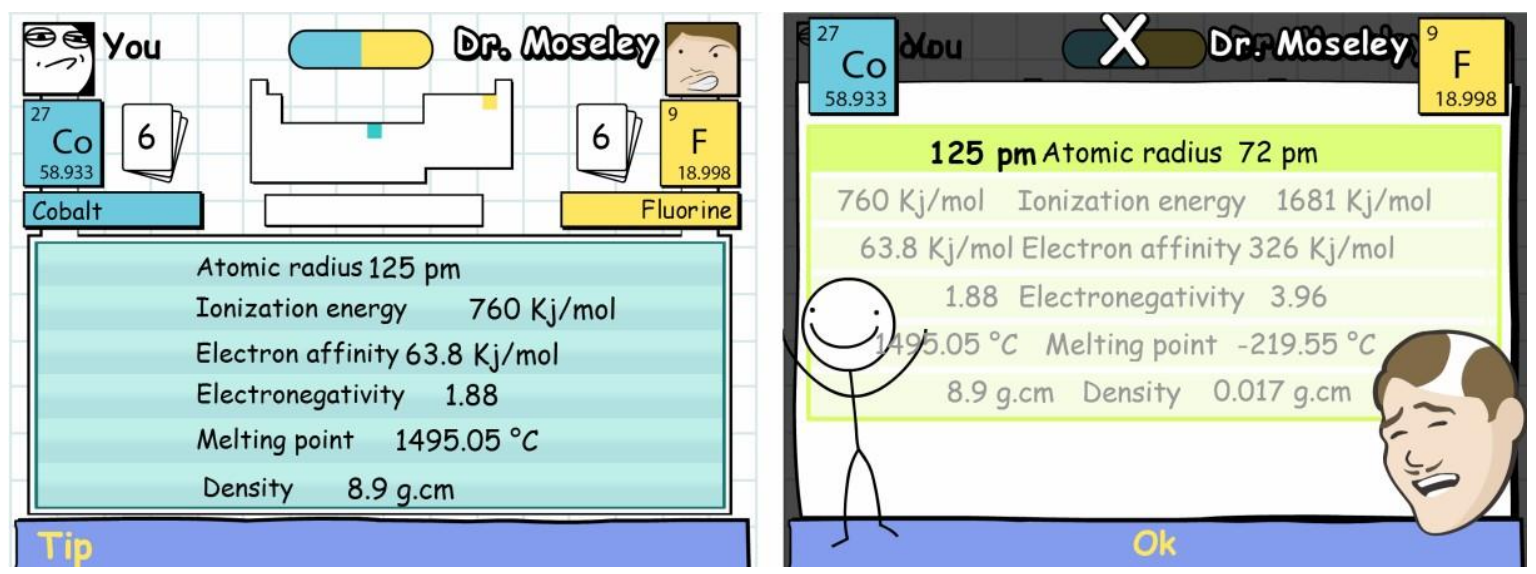

Figure 1. Xenubi's main screens (desktop version).

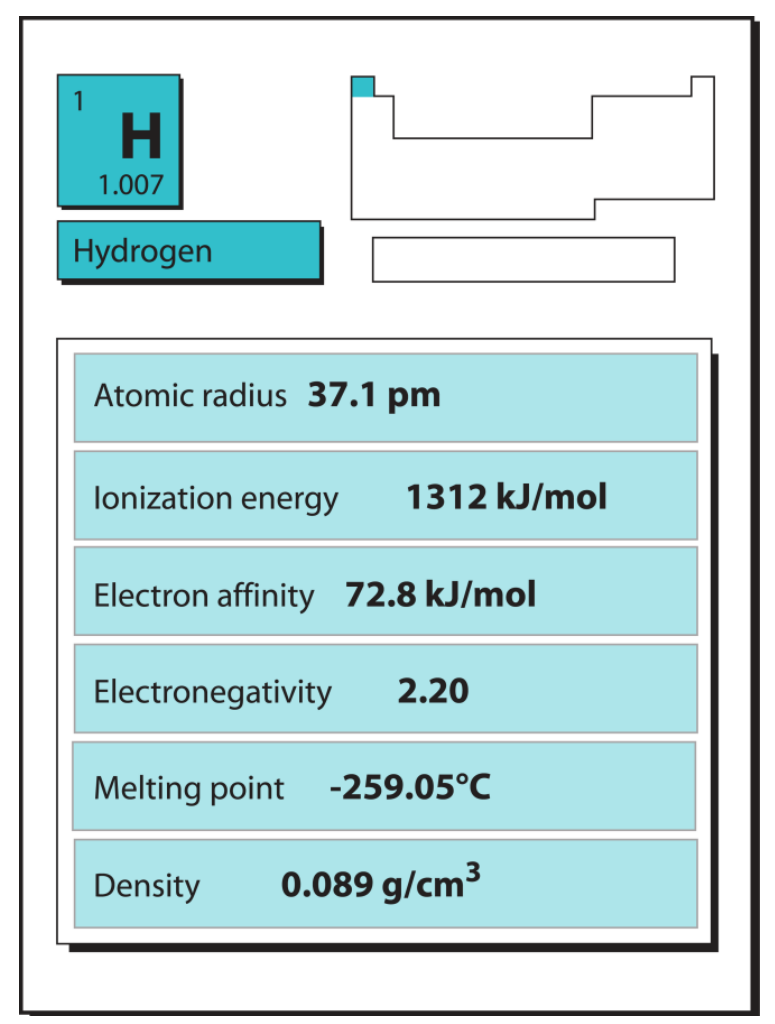


Figure 2. Xenubi's cards (printed version)

The null hypothesis of this study is the learning outcomes of the group playing Xenubi on the computer will be the same as that of the group playing with printed cards. If the null hypothesis is confirmed, Clark's understanding into the debate on the role of media in learning will be supported. If the alternative hypothesis is confirmed, Kozma's proposition will be corroborated.

\section{Materials and methods}

\subsection{Participants}

Students from 5 classes (10th to 11th year) from the same public federal technical school in southern Brazil took part in the evaluation, totaling 139 students. Students from 2 classes took part in the evaluation in 2013; the other 3 classes in 2015 (we could not do it in 2014). Four of these classes had the same teacher and all 5 the same curriculum on Chemistry. No student participated in the experiment twice. The 5 classes comprised 26 students from an Electronic class ( 7 females); 27 students from an Informatics class (10 females); 26 students from an Informatics class (10 females); 37 students from a Management class (25 female); 23 students from a Management class (17 female). The age range was from 15 to 18 years - because the Management classes were in the 10th year, while the Electronics and Informatics in the 11th. Howe ver, this difference is due to the placement of the Chemistry classes in each curriculum, not because they had been taught different content. As this activity was being evaluated by the teacher, mortality was extremely low (5 students), resulting in a samp le of size $\mathrm{n}=134$.

In Brazil, the pre-university schooling system has 12 years: the first 9 years are called "fund amental schooling" and the last 3 are called "medium schooling". Federal schools are better than state schools and equivalent to private schools in learning evaluations.

\subsection{Experimental design and materials}

A repeated measure, pretest-posttest experimental design was used. It is a satisfactory way to control effects that might affect internal validity, i.e. due to learning from students, from test instruments and group selection (Campbell \& Stanley, 1963). The pretest was conducted right after the teacher presented the subject for each class. The pretest and the posttest were similar, with 15 multiple choice questions and a Periodic Table, as depicted by Figure 3. These tests were divided in 2 parts: the first part had 10 questions about POSITION, covering the 6 periodic properties; the second part had 5 questions about CONCEPTS, covering atomic radius and ionization energy - because the values of these 2 properties are inversely proportional, they are easier to understand and are the starting point for understanding how periodic properties are related. Questions about POSITION had different chemical elements in the pre and posttest. Question about CONCEPTS were the same in the pre and posttest, but were presented in a different order. 
PRE-TEST

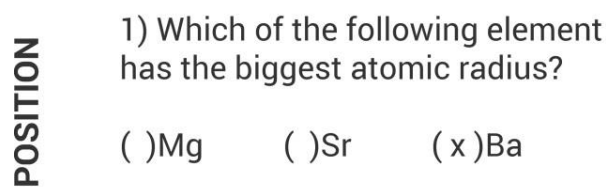

1) Does an atom with a small radius has a high ionization

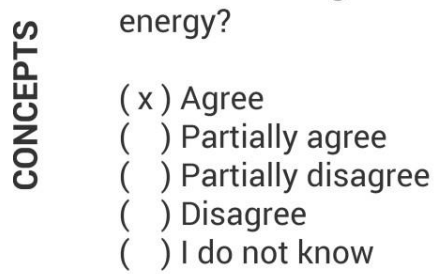

POST-TEST

1) Which of the following element has the biggest atomic radius?

( ) $\mathrm{Na} \quad(\mathrm{x}) \mathrm{Cs} \quad($ ) Li

1) Does an atom with a small radius has a high ionization energy?

(x) Agree

( ) Partially agree

( ) Partially disagree

( ) Disagree

( ) I do not know

Figure 3. Sample questions from the pre and post test.

\section{Results}

To test the hypothesis of difference in the learning outcomes of the two groups (Computer vs. Cards), a Generalized Estimating Equation model (GEE) was used. It uses weighted combinations of longitudinal observations to iteratively estimate the parameters for the regression model (Hanley et al, 2003). The descriptive statistics of the sample (means and standard deviations of the variables, as well as the number of subjects in each group) are shown in Table 1 and Table2. Tables 3 and 4 show the results of the GEE (significance level of $\alpha=0.05$ ).

Table $1 . \mathrm{N}$ umber of subjects, mean and standard deviation for the POSITION variable, per test.

\begin{tabular}{lccc} 
& $n$ & Mean & $\begin{array}{c}\text { Standard } \\
\text { Deviations }\end{array}$ \\
\hline Pre-test Cards & 142 & 6,7 & 0,26 \\
Post-test Cards & 142 & 8,0 & 0,25 \\
\hline Pre-test Computer & 126 & 6,1 & 0,31 \\
Post-test Computer & 126 & 8,1 & 0,27 \\
\hline
\end{tabular}

Table 2. Number of subjects, mean and standard deviation for the CONCEPTS variable, per TEST.

\begin{tabular}{lccc} 
& $n$ & Mean & $\begin{array}{c}\text { Standard } \\
\text { Deviations }\end{array}$ \\
\hline Pre-test Cards & 142 & 4,64 & 0,33 \\
Post-test Cards & 142 & 6,00 & 0,30 \\
\hline
\end{tabular}




\begin{tabular}{|c|c|c|c|}
\hline Pre-test Computer & 126 & 4,48 & 0,40 \\
\hline Post-test Computer & $\underline{126}$ & $\underline{5,74}$ & $\underline{0,35}$ \\
\hline
\end{tabular}

Table 3. Tests of model effects; POSITION

\begin{tabular}{lc} 
& $\mathrm{p}$ \\
\hline GROUP &, 492 \\
TEST &, 000 \\
GROUP * TEST &, 120 \\
\hline
\end{tabular}

Table 4. Tests of model effects; CONCEPTS

\begin{tabular}{lc} 
& $\mathrm{p}$ \\
\hline GROUP &, 641 \\
TEST &, 000 \\
GROUP * TEST &, 914 \\
\hline
\end{tabular}

From Tables 3 and 4 is possible to see that there was no significant GROUP effects, that is, the students playing with Cards and with the Computer had equivalent test performances. Regarding the hypothesis of this investigation, we found no difference when the interaction GROUP*TES T (computers/cards and pre-test/post-test) was analyzed. It means there were no differences if students play the game on the computer or with cards.

There was, however, a significant difference in the TEST variable (before and after playing the game) which points to the conclusion that the game was effective as a learning tool. It was somewhat surprising, however, that students had improved their performance (on the post-test) in the CONCEPTS part of the test.

As the statistical analyses excludes the mere luck possibility, we consider there are two non-exclusive explanations: (1) the students remembered the text in the "tips", available in both versions of the game, therefore answered correctly and/or (2) this improvement might be related to an increased attention and focus on the subject, consequences of engagement and motivation. Perhaps engagement and motivation brought up uncovered memories about the subject, which would remain uncovered unless students actively tried to bring these pieces of information together.

\section{Conclusions}

In this paper we presented an e valuation of learning outcomes with different versions of the same game - a computer version and a printed cards version. The hypothesis that the learning outcomes would be the same for both groups was verified. 
These results are framed within the method-not-media hypothesis, proposed by $\mathrm{C}$ lark (1983, 1994), as they confirm it, and can be counted as yet more evidence that media does not influence learning outcomes, as S ung \& Mayer (2003) and more recently, Furió et al. (2015) also concluded.

Lots of advances on the technical possibilities and an ever increasing access to technology have been happening since $\mathrm{C}$ lark posed his hypothesis. Back in the 80 's, it was extremely expensive and difficult to design (and deliver) educational games. Besides, video games were not as part of our life as they are now - and for this reason designing a good game, with an interesting mechanics was even more difficult than it is today. So we consider reasonable to speculate that the quality of the video games produced today would positively evoke affective state - and perhaps this could be a long lasting effect.

Some limitations on this study restrain the generalization of these results, as listed.

- All students were from the same school, and 4 out of 5 classes had the same teacher. While this is a positive feature of this experiment - because it controls the effects of the independent variable "teacher" - it also borders the conclusion to the students of that particular school.

- We did not test the games against the "traditiona l" method of instruction, i.e. giving a group 50 extra minutes of lecturing on the subject. We did not do that because the sample size would have to be bigger to accommodate one more group in the model.

\section{References}

Campbell, D. T.; Stanley, J.C. (1963). Experimental and Quasi- Experimental Designs for Research on Teaching. In N. L. Gage (ed.), Handbook of Research on Teaching. Chicago: Rand McNally.

Clark, R. E. (1983). Reconsidering Research on Learning from Media. Review of Educational Research, 53(4), 445.

Clark, R. E. (1994). Media Will Never Influence Learning. Educational Technology, Research and Development, 42(2), 21

Demircioğlu, D.; Demircioğlu, G.; Çalik, M. (2009) Investigating the effectiveness of storylines embedded within a context- based approach: the case for the Periodic Table. Chemistry Education: Research and Practice, 10, 241-249

Elking, E. (1930). The Game Of Chemists. Journal of Chemical Education, 7 (3), 636. Fortugno, N. (2008). The Strange Case of the Casual Gamer. IN Isbister, K. \& Schafer, $\mathrm{N}$ (Ed.) Game Usability: Advance from the experts for advancing the player experience. Burlington: Morgan Kaufmann Publishers.

Furió, D., Juan, M. C., Seguít, I., Vivó, R. (2015). Mobile learning vs. traditional classroom lessons: a comparative study. Journal of Computer Assisted Learning, 31 (3), 
189-201.

Gabel, D. (1993). Use of the Particulate Nature of Matter in Developing Conceptual Understanding. Journal of Chemical Education, 70 (3), 193-194.

Hanley, J.; Negassa, A.; Edwardes, M; Forrest er, J. (2003). Statistical analysis of correlated data using generalized esti-mating equations: An orientation. American Journal of Epidemiology, 157(4), 364-375

Joy; E.H.; Garcia, F.E. (2000). Measuring learning effectiveness: A new look at no-significant-difference findings. Journal of Asynchronous Learning Networks, 4 (1), 33-39.

Kozma, R. B. (1991). Learning with media. Review of Educational Research, 61(2), 179-201.

Kozma, R. B. (1994). Will Media Influence Learning? Reframing the Debate. Educational Technology, Research and Development, 42(2), 7-19.

Kozma, R. B.; Russel, J. (1997). Multimedia and Understanding: Expert and Novice Responses to Different Representations of Chemical P henomena. Journal of Research in Science Teaching, 34 (9), 949-968.

Lazonder, A.W.;. Ehrenhard, S. (2014). Relative effectiveness of physical and virtual manipulatives for conceptual change in science: how falling objects fall. Journal of Computer Assisted Learning, 30, 110-120.

Liu, Y.; Dwi-N ugroho, A. (2012). The social semiotic construction of chemical periodicity: A multimodal view. Semiotica, 190, 133-151

Martí-Centelles, V., \& Rubio-Magnieto, J. (2014). ChemMend: A card game to introduce and explore the periodic table while engaging students' interest. Journal of Chemical Education, 91(6), 868-871

Mayer, R. (2001). Multimedia Learning. Cambridge Press.

Mayer, R. E.; Moreno, R. (1998). A cognitive theory of multimedia learning: impli-cations for design principles. ACM SIGCHI Conference on Human Factors in Computing Systems, 1-10.

Moreno, L. F., Hincapié, G., \& Alzate, M. V. (2014). Cheminoes: A didactic game to learn chemical relationships between valence, atomic number, and symbol. Journal of Chemical Education, 91(6), 872-875.

Scerri, E. R. (2007). The Periodic Table: Its Story And Its Significance. Oxford University Press: New York.

Sevcik, R. S.; Hicks, O’Dell; Schultz, L. D. (2008). Elements - Card Game of Chemical Names and Symbols. Journal of Chemical Education, 85(4), 514-515.

Sung, E. \& Mayer, R.E. (2013). Online multimedia learning with mobile devices and 
desktop computers: An experimental test of Clark's methods-not-media hypothesis. Computers in Human Behavior, 29(3), 639-647.

Welsch, M. J. (2003). Organic Functional Group Playing Card Deck. Journal of Chemical Education, 80(4), 426-427. 